\title{
Input Voltage Modulated High Voltage DC Power Supply Topology for Pulsed Load Applications
}

\author{
N.Vishwanathan, Dr. V.Ramanarayanan \\ Power Electronics Group, Dept. of Electrical Engineering, \\ IISc., Bangalore -- 560 012, India. \\ e-mail: nvn@ee.iisc.ernet.in, e-mail: vram@ee.iisc.ernet.in
}

\begin{abstract}
High voltage power supplies for radar applications are investigated which are subjected to pulsed load with stringent specifications. In the proposed solution, power conversion is done in two stages. A low power-high frequency converter modulates the input voltage of a high power-low frequency converter. This method satisfies all the performance specifications and takes care of the critical aspects of $\mathrm{HV}$ transformer.
\end{abstract}

\section{INTRODUCTION}

High voltage (HV) power supplies are used in industrial, medical, and air borne applications [1], [2], [4]. In many high-power, high-voltage applications such as TWT, laser based systems, X-ray equipment, radar power supplies, high quality power is required. In addition, radar power supplies are subjected to pulsed load.

$\mathrm{HV}$ transformer is a crucial element in $\mathrm{HV}$ power converters due to large no. of secondary turns and insulation requirements, which exacerbate its non-idealities like winding capacitance and leakage inductance. Attempts have been made to absorb these non-idealities as useful elements. It has resulted in series, parallel, and series-parallel resonant converters (i.e., SRC, PRC, \& SPRC respectively) with their own advantages and disadvantages. These can be controlled either by frequency modulation or constant frequency phasemodulation [6]. Phase modulation is generally preferred due to constant switching operation, which yields optimum design of reactive elements. Phase modulated resonant converter, equivalent ckt. of the $\mathrm{HV}$ transformer and various resonant tank circuits are shown in figs. 1, 2 and 3 respectively.

The SRC is free from possible saturation of $\mathrm{HV}$ transformer and allows capacitive filter at the output. It absorbs the leakage inductance of the HV transformer. It gives high efficiency over a wide range of load. Though transformer winding capacitance is not absorbed in the tank ckt., SRC has been used in the high-voltage, high-power converters due to several other advantages [4].

The PRC absorbs the winding capacitance into the resonant tank ckt. But it requires an LC filter at the output, which is prohibitive due to size constraint. It has been shown in [3] that it is possible to remove this component without degrading the performance. Even then the PRC has the limitations like, transformer saturation in full bridge topology and low efficiency at light loads.

The SPRC combines the advantages of both SRC \& PRC. The output is controllable for no-load or light-loads, and the light load efficiency is high. In [5], it has been proposed for pulsed load application. It absorbs all the parasites of the HV transformer. But the hybrid converters are complex to analyze and difficult to control.

This paper presents a converter topology for highvoltage DC power supplies subjected to pulse loads with stringent performance specifications demanding tight output voltage regulation and high efficiency. Radar power supplies are subjected to pulse load with high pulse repetition frequency (PRF). Table I and fig.4 describe the specifications used for the prototype. Actual application requires an output voltage and power level of $22 \mathrm{KV}$ and $1.25 \mathrm{KW}$.

As the load switches at high frequency, the converter should switch at-least at twice the load switching frequency for good regulation and stable operation. Tackling high frequency, high voltage, high power and tight regulation in one power converter is a challenging issue. The combination of "high power \& high frequency inverter" and "high frequency \& high voltage transformer" is critical resulting in number of compromises in terms of output regulation, response time, etc. The problems encountered in general with high voltage and high frequency transformer are: 1) Insulation failure, 2) Skin \& proximity effect resulting in increased copper losses and temperature rise, 3) Increased iron losses, 4) Parasites of HV transformer i.e., leakage reactance results in poor regulation and secondary winding capacitance results in current spikes and delay.

Above mentioned drawbacks lead to the development of an input voltage modulated (IVM) power conversion. In this topology, a low power-high frequency converter modulates the input voltage of a high power-low frequency converter, which produces the final output voltage. This two-stage power conversion helps in overcoming the problems of HV \& HF transformer, provides fast response and good regulation without compromising the efficiency constraint.

\section{PHASE-MODULATED SERIES RESONANT CONVERTER}

Phase-modulated series resonant converter (PM-SRC) is very suitable for high-voltage DC power supplies. The converter switches at a frequency slightly higher than the resonant frequency of the tank circuit, facilitating ZVS of the devices with the aid of the capacitors connected across them. PM-SRC operates in three modes, namely, mode-1, mode-2, and mode-3. The relevant waveforms of the tank current, $\mathrm{i}(\mathrm{t})$, inverter output voltage, $\mathrm{v}_{\mathrm{AB}}$, resonant capacitor voltage, $v_{c}(t)$, and output voltage, $v_{O}$, under the three modes are shown in fig.5. The various sub-periods are shown as A, $\mathrm{B}, \mathrm{C}, \mathrm{D}$, and $\mathrm{E}$. The general equations describing the $\mathrm{LC}$ tank circuit with excitation $\left(\mathrm{V}_{\mathrm{in}}-\mathrm{V}_{\text {out }}\right)$ are given by 


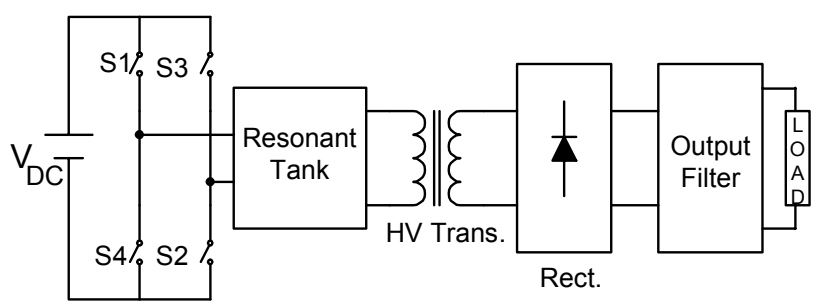

Fig. 1

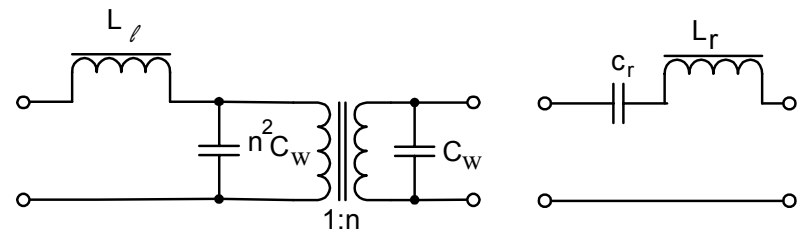

Fig. 2

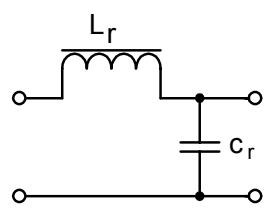

Fig. 3 (b)

Fig. 3 (c)

TABLE I

$\begin{array}{ll}\text { Supply Voltage: } 270 \mathrm{VDC} \pm 10 \% & \text { Regulation: }<0.01 \% \\ \text { Output Voltage: } 1 \mathrm{KV} & \text { Droop: } 0.5 \mathrm{~V} / \mu \mathrm{sec} . \\ \text { Peak Power: } 6 \mathrm{KW} & \text { Load Switching Freq.: } 125 \mathrm{~K} \mathrm{HZ} \\ \text { Average Power: } 600 \mathrm{~W} & \text { Efficiency: }>85 \%\end{array}$

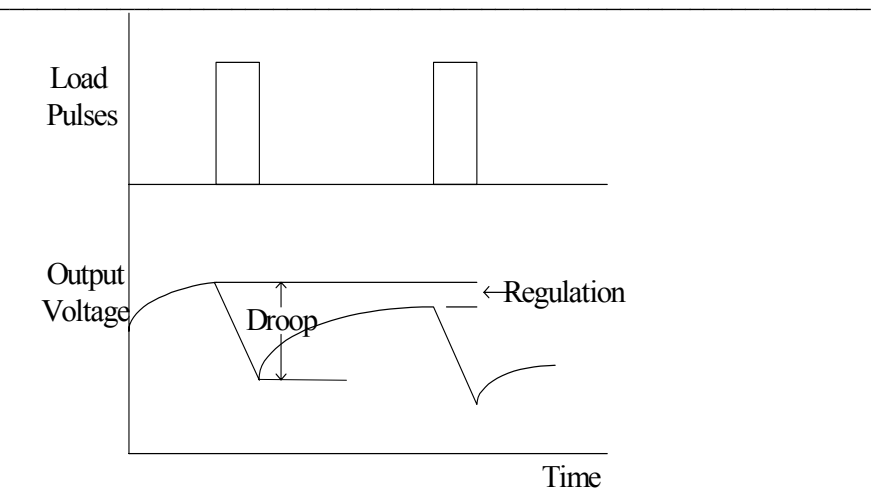

Fig. 4

$$
\begin{aligned}
i(t)= & I(0) \cos \omega_{r} t+\frac{\left[\left(V_{\text {in }}-V_{\text {out }}\right)-V_{c}(0)\right]}{Z_{c}} \sin \omega_{r} t \\
v_{c}(t)= & -\left[\left(V_{\text {in }}-V_{\text {out }}\right)-V_{c}(0)\right] \cos \omega_{r} t+Z_{c} I(0) \sin \omega_{r} t \\
& +\left(V_{\text {in }}-V_{\text {out }}\right)
\end{aligned}
$$

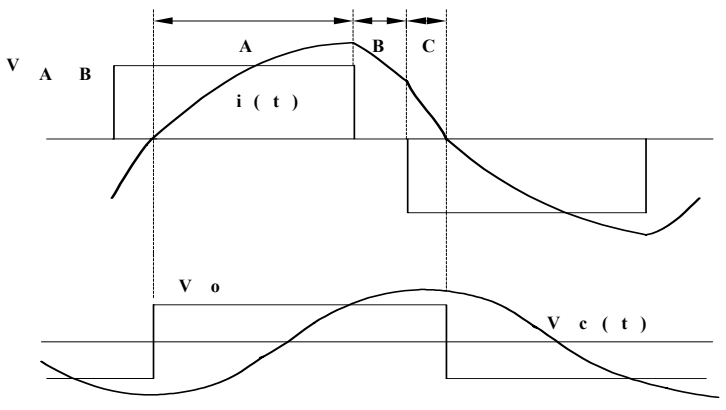

(a) Mode-1 operation

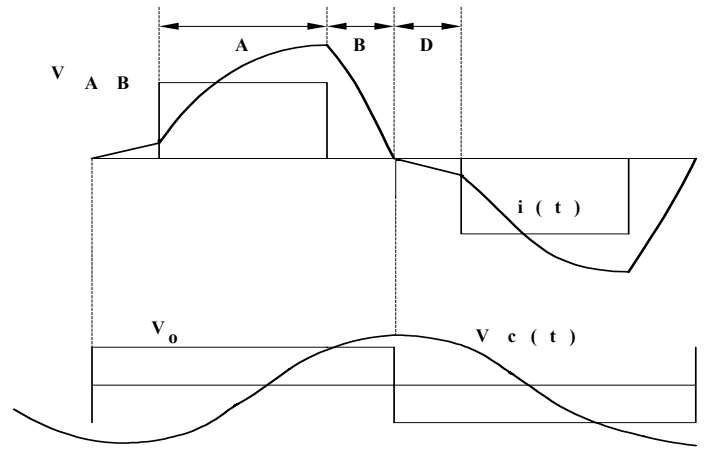

(b) Mode- 2 operation

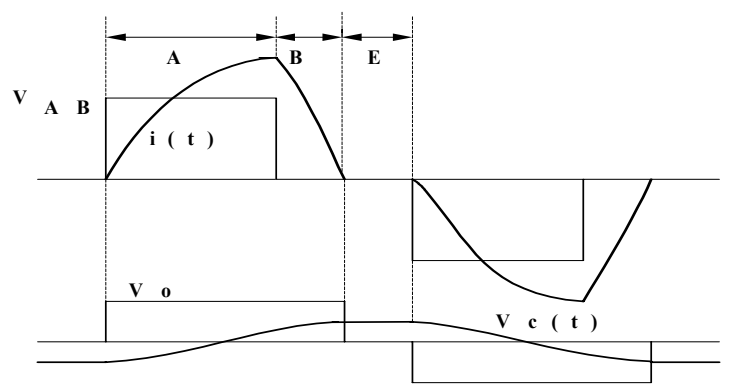

(c) Mode -3 operation

Fig. 5. Waveforms of PM-SRC

$I(0)$ and $V_{c}(0)$ are initial values of $i(t)$ and $V_{c}(t)$ respectively. $\mathrm{Z}_{\mathrm{c}}$ is the characteristic impedance of the LC ckt., and $\omega_{\mathrm{r}}$ is the resonant frequency. Current and voltage equations for each of the sub-period in different intervals are obtained by substituting the appropriate values of input $\&$ output voltage and initial conditions in the above equations.

\section{INPUT VOLTAGE MODULATED (IVM) POWER CONVERTER}

The block diagram of the proposed topology for the pulsed load application is shown in fig.6. In this topology, one of the converters, named as Base Power Supply (BPS), is an uncontrolled converter \& the other, named, as Fast Power Supply (FPS) is a controlled converter. Both BPS and FPS are phase-modulated series resonant converters. The final output voltage is provided by the BPS. The input voltage to the BPS is provided as the sum of primary DC supply voltage and output of the FPS. This gives a simple configuration for the overall system with only one feedback loop. As the BPS 
is pulse loaded with fixed duty cycle, the average load on BPS is constant. Under constant frequency of operation and fixed duty cycle of BPS, its gain can be considered as constant. Controlling the input of BPS through FPS regulates the final output voltage. The transformer insulation is subjected to HV at $62.5 \mathrm{kHz}$, which is within the safe limit.

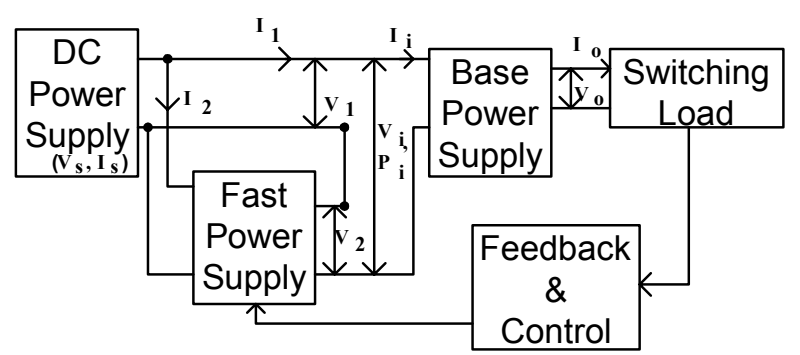

Fig. 6. IVM Power Converter

Let, $\mathrm{f}_{\mathrm{B}}=$ switching frequency of the base power supply, $\mathrm{f}_{\mathrm{F}}=$ switching frequency of the fast power supply, and $\mathrm{f}_{\mathrm{L}}=$ switching frequency of the load.

BPS is switched at a frequency such that load-switching frequency is its integral multiple. FPS is switched at one order of magnitude higher than BPS. $\mathrm{f}_{\mathrm{B}}=\mathrm{f}_{\mathrm{L}} / \mathrm{n}, \mathrm{n}$ is an integer, and $\mathrm{f}_{\mathrm{F}}=10 \times \mathrm{f}_{\mathrm{B}}$. The values of $\mathrm{f}_{\mathrm{B}}, \mathrm{f}_{\mathrm{F}}, \& \mathrm{f}_{\mathrm{L}}$ are 62.5 $\mathrm{kHz}, 625 \mathrm{kHz}$, and $125 \mathrm{kHz}$ respectively. This type of frequency selection avoids the sub-harmonic oscillation in the final output voltage and provides fast response.

\section{VOLTAGE \& POWER RATINGS FOR BPS \& FPS AND OVERALL WFFICIENCY}

\section{A. Voltage and Power Ratings}

These ratings for BPS \& FPS are based on the supply voltage variation from the nominal value. Assuming the converters to be loss less, it can be observed from fig. 6 that percentage of the voltage produced by FPS is same as the percentage of power handled by it. These percentages have to be calculated with respect to the total input voltage and total input power of the BPS.

The magnitude of droop due to pulse load is negligible in comparison to the output voltage.

Let, $\quad \%$ variation of the source voltage $= \pm \mathrm{X}$

$$
\begin{aligned}
& \mathrm{V}_{1}=\mathrm{V}_{\mathrm{S}}=\text { nominal source voltage } \\
& \mathrm{V}_{\mathrm{i}}=\left(\mathrm{V}_{1}+\mathrm{V}_{2}\right), \mathrm{V}_{2}=\left(\mathrm{V}_{\mathrm{i}}-\mathrm{V}_{1}\right)
\end{aligned}
$$

From the control aspect, for keeping $\mathrm{V}_{\mathrm{i}}$ constant, max. Value of $V_{2}$ is produced under min. value of $V_{S}$.

$$
\mathrm{V}_{\mathrm{i}}=(1+\mathrm{X}) \mathrm{V}_{\mathrm{S}}=\text { Constant }
$$

Min. value of source voltage $=\mathrm{V}_{1, \min }=(1-\mathrm{X}) \mathrm{V}_{\mathrm{S}}$

Max. Value of $\mathrm{V}_{2}=\mathrm{V}_{2}$,max. $=\left(\mathrm{V}_{\mathrm{i}}-\mathrm{V}_{1, \text { min. }}\right)=2 \mathrm{XV} \mathrm{V}_{\mathrm{S}}$

$$
\frac{\mathrm{V}_{2, \max }}{\mathrm{V}_{\mathrm{i}}}=\frac{2 \mathrm{X}}{(1+\mathrm{X})} \text {, and } \frac{\text { Max.output of FPS }}{\mathrm{P}_{\mathrm{i}}}=\frac{2 \mathrm{X}}{1+\mathrm{X}}
$$

Max. $\%$ of voltage to be produced by FPS $=\frac{2 \mathrm{X}}{(1+\mathrm{X})} \times 100$

Max. $\%$ of power to be handled by the FPS $=\frac{2 \mathrm{X}}{(1+\mathrm{X})} \times 100$

For $10 \%$ variation in $\mathrm{Vs}, \mathrm{V}_{2}$ has to be $18.18 \%$ of $\mathrm{V}_{\mathrm{i}}$ and power rating of FPS has to be $18.18 \%$ of Pi.

\section{B. Overall efficiency ( $\eta)$}

From the fig. (6), the following expressions can be written.

$$
\begin{aligned}
& \mathrm{V}_{\mathrm{O}} \mathrm{I}_{\mathrm{O}}=\eta_{1}\left(\mathrm{~V}_{1}+\mathrm{V}_{2}\right) \mathrm{I}_{1} \\
& \mathrm{~V}_{2} \mathrm{I}_{1}=\eta_{2}\left(\mathrm{~V}_{1} \mathrm{I}_{2}\right) \\
& \eta=\frac{\mathrm{V}_{\mathrm{O}} \mathrm{I}_{\mathrm{O}}}{\mathrm{V}_{\mathrm{S}} \mathrm{I}_{\mathrm{S}}}=\frac{\mathrm{V}_{\mathrm{O}} \mathrm{I}_{\mathrm{O}}}{\mathrm{V}_{1}\left(\mathrm{I}_{1}+\mathrm{I}_{2}\right)}
\end{aligned}
$$

Using eq.(3) and (4) in eq.(5),

$$
\eta=\frac{\eta_{1}\left(V_{1}+V_{2}\right)}{V_{1}+\frac{V_{2}}{\eta_{2}}}=\frac{\eta_{1}\left(1+\frac{V_{2}}{V_{1}}\right)}{1+\frac{V_{2}}{V_{1}} \frac{1}{\eta_{2}}}
$$

Putting $\frac{\mathrm{V}_{2}}{\mathrm{~V}_{1}}=\mathrm{K}$ in eq.(6),

Overall efficiency $(\eta)=\frac{\eta_{1} \eta_{2}(1+K)}{\left(\eta_{2}+K\right)}$.

\section{DESIGN CONSIDERATIONS}

PM-SRC is used in both BPS \& FPS. Its design mainly involves the selection of resonant tank elements ( $\mathrm{Lr} \& \mathrm{Cr}$ ) and transformer turns ratio (n). For this, all the parameters in the PM-SRC are normalized with respect to the base values. Table II gives the list of the variables and corresponding base values.

TABLE II Base Variables

\begin{tabular}{lc}
\hline \multicolumn{1}{c}{ Variables } & Base Values \\
\hline Voltage & Input DC Voltage, $\mathrm{V}_{\mathrm{DC}}$ \\
Resistance & Tank Char. Impedance, $\mathrm{Z}_{\mathrm{c}}$ \\
Current & $\mathrm{I}_{\mathrm{B}}=\mathrm{V}_{\mathrm{DC}} / \mathrm{Z}_{\mathrm{c}}$ \\
Frequency & Resonant frequency, $\omega_{\mathrm{r}}$ \\
Capacitance & $\mathrm{C}_{\mathrm{r}}$ \\
Inductance & $\mathrm{L}_{\mathrm{r}}$ \\
& \\
\hline
\end{tabular}

Thus the per unit values are $\mathrm{V}_{\mathrm{DC}}=1.0$ p.u., $\omega_{\mathrm{r}}=1.0$ p.u., $\mathrm{L}_{\mathrm{r}}=1.0$ p.u., $\mathrm{C}_{\mathrm{r}}=1.0$ p.u.

$$
\text { gain of the converter }(M)=\frac{V_{O}}{n \cdot V_{D C}}
$$

where $\mathrm{V}_{\mathrm{O}}=$ output voltage.

Performance of the PM-SRC depends on various parameters like $L_{r}, C_{r}, \omega_{r}$, switching frequency $\left(\omega_{\mathrm{s}}\right)$, load resistance $\left(R_{L}\right)$, duty cycle (D), and transformer turns ratio (n). To take into account the effect of these parameters, these are grouped together as follows: 


$$
\begin{gathered}
\gamma=\frac{\omega_{\mathrm{S}}}{\omega_{\mathrm{r}}} \\
\zeta=\frac{\mathrm{Zc}}{\mathrm{R}_{\mathrm{L}^{\prime}}}
\end{gathered}
$$

where $\mathrm{Z}_{\mathrm{c}}=\sqrt{\mathrm{L}_{\mathrm{r}} / \mathrm{C}_{\mathrm{r}}}$ and $\mathrm{R}_{\mathrm{L}^{\prime}}=\frac{\mathrm{R}_{\mathrm{L}}}{\mathrm{n}^{2}}$

The two variables $\gamma$ and $\zeta$ are used to study the performance of the PM-SRC. As it is operated above resonant frequency, its operation for $\gamma>1$ is studied. These two variables are varied to find the voltage stress on the tank capacitor, current stress on the tank circuit and voltage gain of the converter. Their effects are summarized in the following tables. Tables III\& IV give the effects of $\gamma$ and $\zeta$ respectively on the performance of PM-SRC.

\section{TABLE III}

\begin{tabular}{cccc}
\hline$\gamma$ & $\mathrm{M}$ & Voltage stress & Current stress \\
\hline 1.05 & 1.958 & 1.948 & 1.969 \\
1.1 & 1.859 & 1.769 & 1.831 \\
1.4 & 1.238 & 0.930 & 1.31 \\
1.8 & 0.8178 & 0.478 & 0.99 \\
2.0 & 0.709 & 0.378 & 0.88 \\
\hline
\end{tabular}

For studying the effect of $\gamma$, the values of $\zeta, \mathrm{n}$, and $\mathrm{D}$ are selected as $1 / 3,1$, and 1 respectively. Table III shows that gain of the converter increases as the value of $\gamma$ tends to unity. Operation of the PM-SRC with $\gamma$ close to unity results in higher voltage and current stresses. If components with these values are available, then operation under this condition may be adopted as it results in higher gain of the converter and lower turns ratio of the transformer. Operation under $\gamma=1$ is not preferable as it results in loss of ZVS and SRC loses its inherent short circuit protection. To have all the advantages of higher gain, ZVS, and inherent short circuit protection, operation with $\gamma=1.05$ is selected. Table IV shows the effect of $\zeta$ on the performance of PM-SRC. During this study, the values of $\gamma, \mathrm{D}$, and $\mathrm{n}$ are fixed at $1.05,1$, and 1 respectively. As $\zeta$ decreases below unity, the voltage gain increases while the voltage and current stresses are decreased. Thus the operation of PM-SRC for $\zeta<1$ is preferred.

$\zeta=1 / 6$ is preferred as it results in a voltage gain close to 2 . It is the max. gain of SRC with voltage doubler at the output. The stresses on tank elements are less than 1 p.u. For BPS, which is operating in a square wave mode, fixed input voltage, and with voltage doubler, the design parameters are $\gamma=1.05, \zeta=1 / 6$ and $\mathrm{M}=1.987$. For FPS, which is also a PMSRC but without voltage doubler is operating under variable duty cycle. The design is carried out under low line and full load. BPS \& FPS can be designed using equations (7), (8), (9), selected design parameters, and power ratings of the individual converters.
TABLE IV

\begin{tabular}{cccc}
\hline$\zeta$ & $\mathrm{M}$ & Voltage stress & Current stress \\
\hline 3 & 1.117 & 10.05 & 10.48 \\
1 & 1.772 & 5.305 & 5.42 \\
$1 / 2$ & 1.918 & 2.879 & 2.915 \\
$1 / 4$ & 1.975 & 1.479 & 1.49 \\
$1 / 6$ & 1.987 & 0.98 & 0.99 \\
\hline
\end{tabular}

The values of the components obtained are:

For BPS: $\mathrm{L}_{\mathrm{r}}=260.08 \mu \mathrm{H}, \mathrm{C}_{\mathrm{r}}=27.5 \mathrm{nF}, \mathrm{n}=1.69$

For FPS: $\mathrm{L}_{\mathrm{r}}=23.38 \mu \mathrm{H}, \mathrm{C}_{\mathrm{r}}=3.05 \mathrm{nF}, \mathrm{n}=0.22$

$$
\text { VI. RESULTS }
$$

Simulation results of the proposed topology under closed loop are shown in figs. 7(a) to 7(g) and experimental results are shown in figs. $8(\mathrm{a})$ to $8(\mathrm{f})$.

In fig. 8(a) voltage is at $200 \mathrm{~V} / \mathrm{div}$. and current is at $5 \mathrm{~A} / \mathrm{div}$. In figs. $8(\mathrm{~b}), 8(\mathrm{c})$, and $8(\mathrm{~d})$ voltage is at $100 \mathrm{~V} / \mathrm{div}$. and current is at $2 \mathrm{~A} / \mathrm{div}$. In fig. $8(\mathrm{e})$ voltage is at $200 \mathrm{~V} / \mathrm{div}$. In fig. $8(\mathrm{f})$ voltage is at $500 \mathrm{mV} / \mathrm{div}$.

Simulation and experimental results are found to be in agreement with each other. As the input voltage of the BPS is obtained as the sum of primary supply voltage and output of FPS, the switching noise injected in the supply voltage due to FPS is reflected in the waveforms of BPS in fig. 8(a). The same effect can be observed in the droop waveform of output voltage in fig. 8(f). Peak to peak Switching noise in the Output voltage is observed to be $3.5 \mathrm{~V}$ at $1 \mathrm{KV}$.

\section{CONCLUSIONS}

The proposed converter topology is studied under various conditions of line and load. The output voltage is regulated with the modulation of input voltage to BPS. BPS handles the total power but the FPS handles only $18.18 \%$ of the total power. Hence the overall efficiency is mainly dictated by BPS, which is close to $92 \%$. The regulation is observed to be less than $0.01 \%$ and droop is less than $0.4 \mathrm{~V}$. Under the step change of the supply voltage from min. to max. (243V to $297 \mathrm{~V})$ the output voltage settles back in $4.89 \mathrm{msec}$. with an overshoot of $1.8 \%$. Under varying conditions of the supply voltage, input to the BPS, which is sum of the supply voltage and output of the FPS is always maintained at $297 \mathrm{~V}$ as per the control requirement. As input voltage of BPS is controlled to be constant, it always operates in continuous conduction (MODE-1) ensuring ZVS under all conditions of line and load. For the FPS, as its duty cycle may change under various operating conditions, the range of ZVS is extended by external means. Finally, the BPS and FPS put together give high efficiency and satisfy all the performance requirements. 

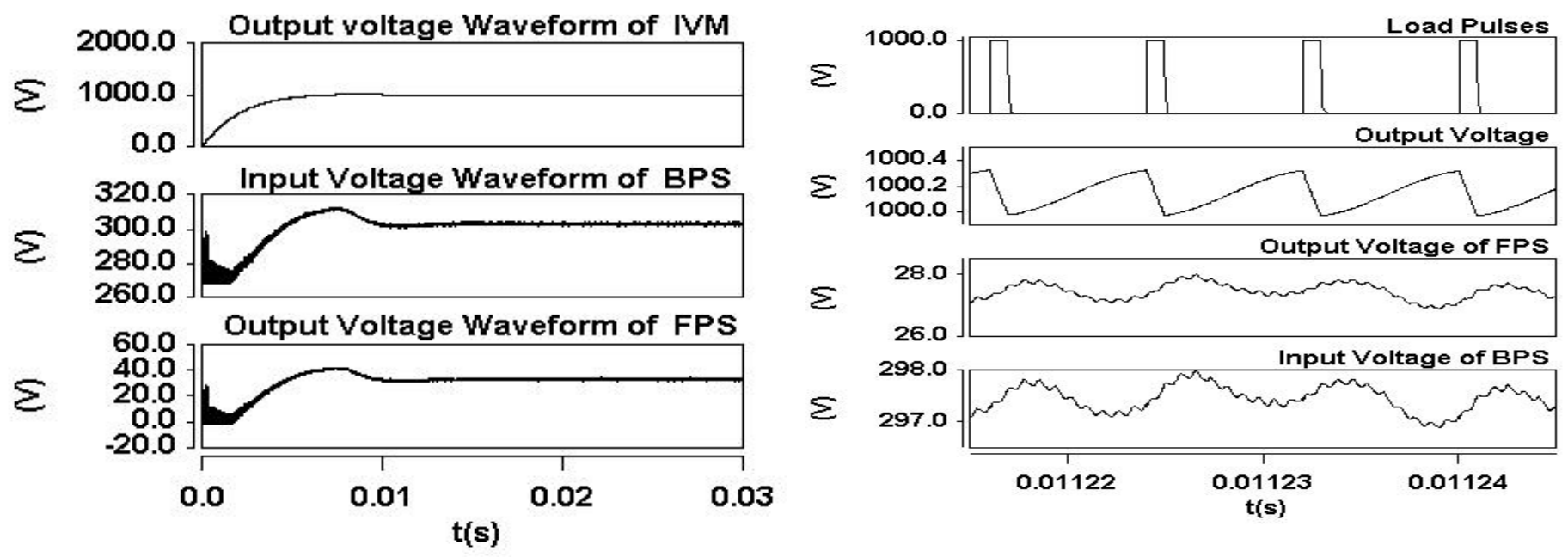

Fig. 7(a) Waveforms Under Nominal Supply Voltage (270 V)

Fig. 7(b) Enlarged Waveforms of Fig. 7(a) with Load Pulses
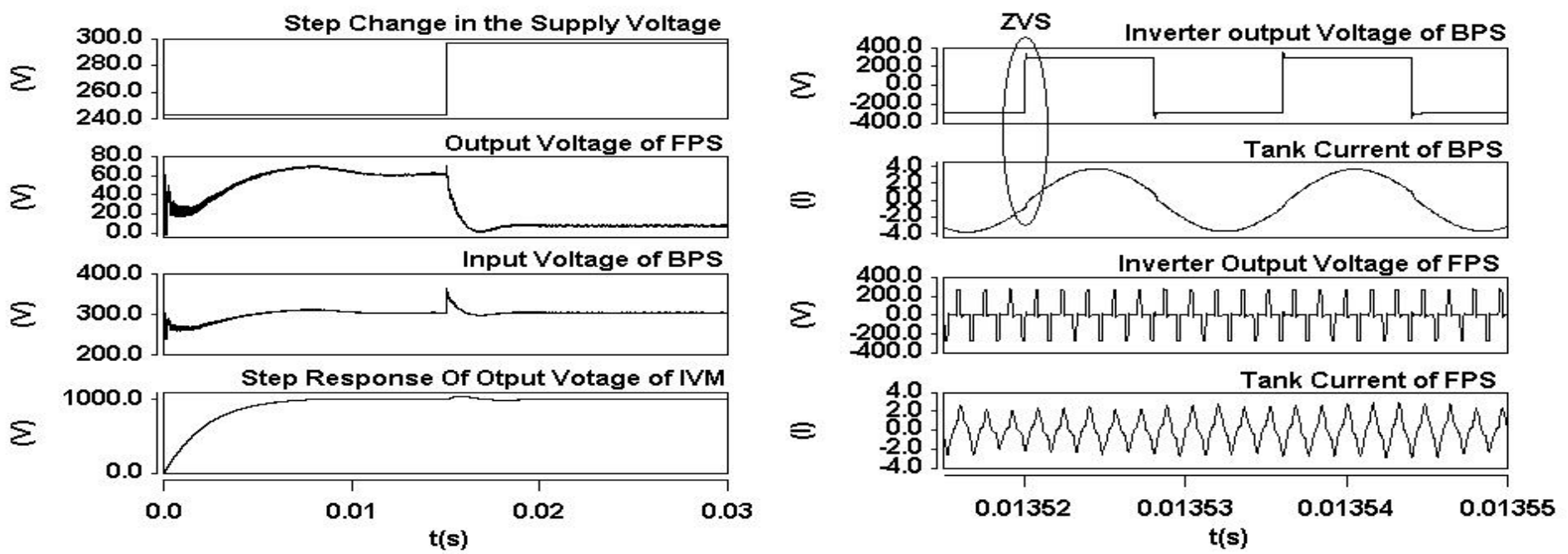

Fig. 7(c) Step response for a Step Change from 243V to 297V

Fig. 7(d) Waveforms of Inverter Output Voltages \& Tank Currents at 270V
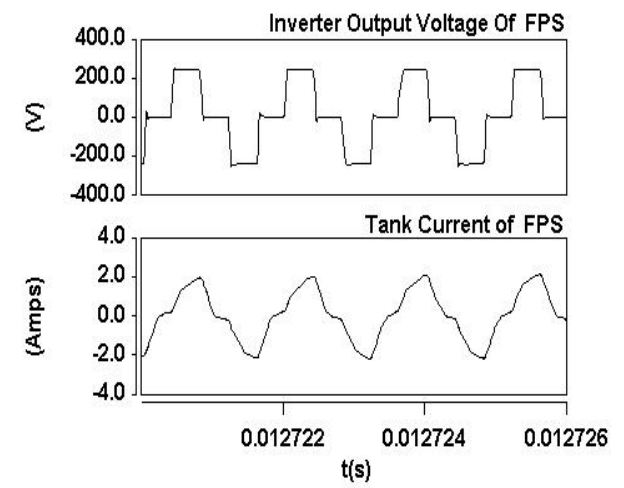

Fig. 7(e) Waveforms of FPS at 243V
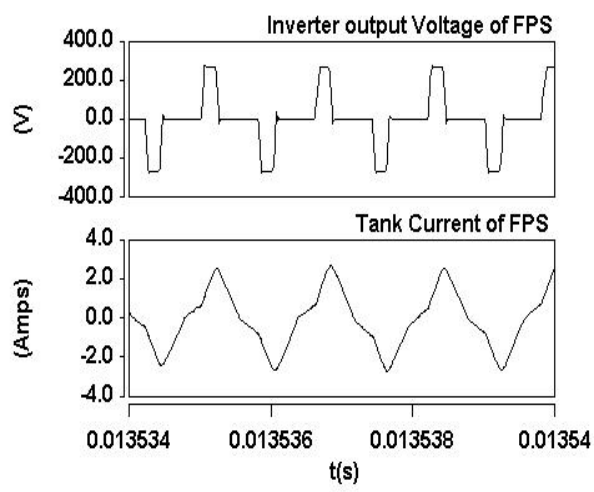

Fig. 7(f) Waveforms of FPS at 270V
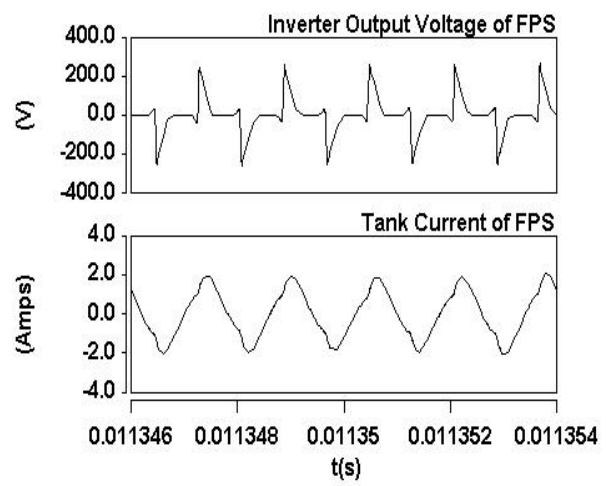

Fig. 7(g) Waveforms of FPS at 297V 


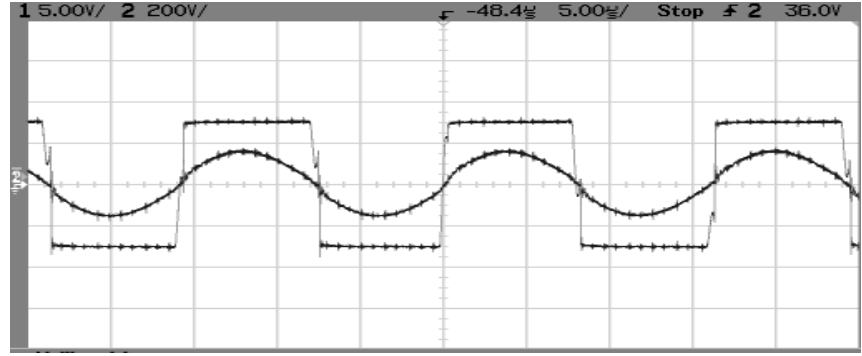

Fig. 8(a) BPS Waveforms of Inverter Output Voltage \& Tank Current at 297V

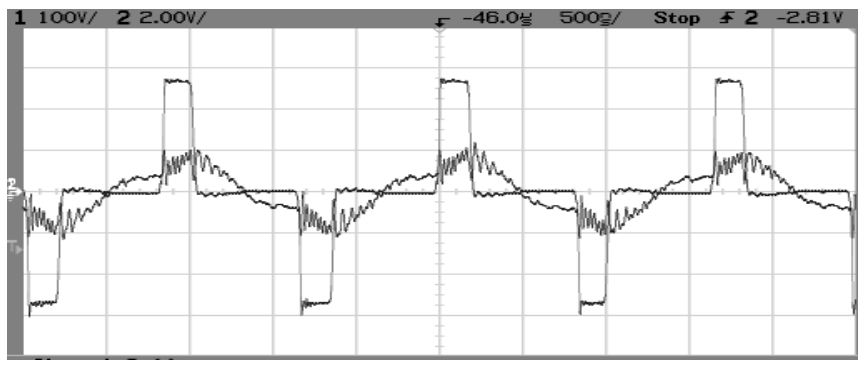

Fig. 8(c) FPS Waveforms of Inverter Output Voltage \& Tank Current at 270V

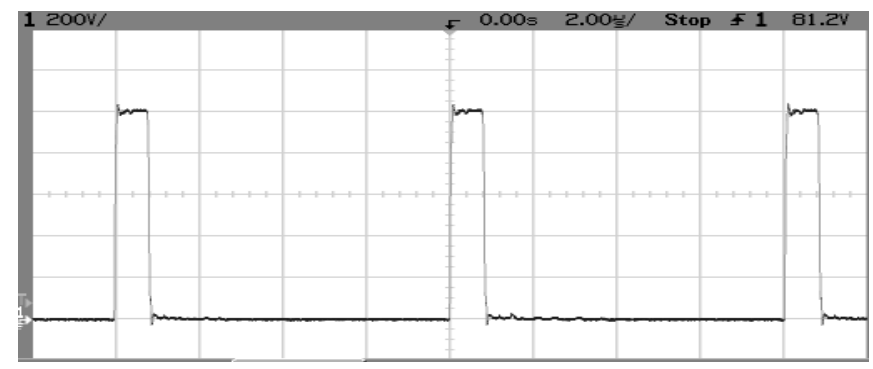

Fig. 8(e) Load Pulses at $1 \mathrm{KV} \& 125 \mathrm{KHz}$

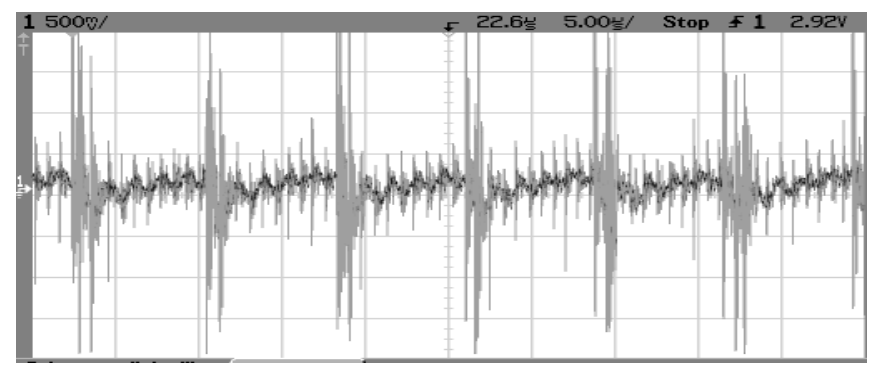

Fig. 8(f) Output Voltage Droop with Pulse Load at 1KV

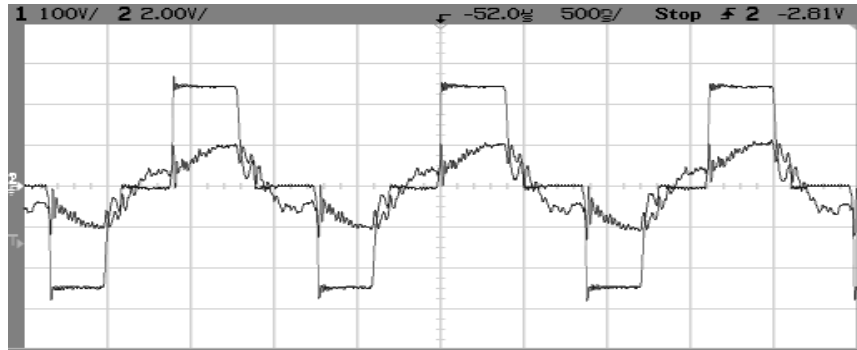

Fig. 8(b) FPS Waveforms of Inverter Output Voltage \& Tank Current at 243V

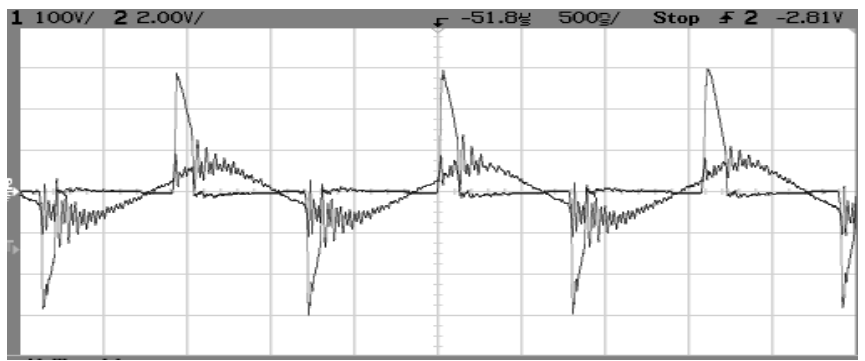

Fig. 8(d) FPS Waveforms of Inverter Output Voltage \& Tank Current at 297V

\section{REFERENCES}

[1] A.S. Rostad, C.T.Mc Cown, and D.O. Lawrence, “ Application of the Venable converter to a series of Satellite TWT power processors," in IEEE - PESC , 1976, pp. $104-111$.

[2] B.P.Israelsen, J.R. Martin, C.R. Reeve and V.S. Scown, “ A $2.5 \mathrm{KV}$ high - reliability TWT power supply: Design techniques for high efficiency and low ripple," in IEEE PESC, 1977, pp.212 - 222.

[3] S.D. Johnson, A.F. Witulski, and R.W. Erickson, “ Comparison of resonant topologies in high voltage DC applications," in IEEE Trans. on Aero. And Elect. Systems, vol.24, No.3, May 1988, pp.263 - 274.

[4] Y. Cheron, H.Foch, and J. Salesses, " Study of a resonant converter using power transistor in a $25 \mathrm{KW} \mathrm{X} \mathrm{-} \mathrm{ray} \mathrm{tube}$ power supply," in IEEE - PESC , 1985, pp. 295 - 306.

[5] V. Garcia, M. Rico, M.M. Hernando, and J. Uceda, " An optimized DC to DC converter topology for high voltage pulse load applications," in IEEE - PESC, 1994, pp. 1413 $-1421$.

[6] I.J. Pitel, “ Phase - modulated resonant power conversion techniques for high frequency inverters," in IEEE Trans. on Ind. Appl., 1986,vol.22, pp. $1044-1051$. 